Thajudeen. S., Lennartsson. M., and Elgh. F., (2018). "Impacts on the design phase of industrial housing when applying a product platform approach." In: Proc. $26^{\text {th }}$ Annual Conference of the International. Group for Lean Construction (IGLC), González, V.A. (ed.), Chennai, India, pp. 527-537. DOI: doi.org/10.24928/2018/0281. Available at: www.iglc.net.

\title{
IMPACT ON THE DESIGN PHASE OF INDUSTRIAL HOUSING WHEN APPLYING A PRODUCT PLATFORM APPROACH
}

\author{
Shamnath. Thajudeen', Martin. Lennartsson ${ }^{2}$, and Fredrik Elgh ${ }^{3}$
}

\begin{abstract}
With a glulam-based post-beam building system, a variety of building solutions is offered on the market for multi-story buildings. The building system must be adaptable to the demands of each project. However, short lead-time, efficient manufacturing and assembly must be ensured. The use of product platforms has been acknowledged as an enabler to manage external (customer) and internal (production) efficiency. The building system cannot be locked to a set of standard components as a high level of customisation is required. A set of methods and tools is needed to support the design work and to ensure that solutions stay inside the boundaries of the platform definition. The aim of this work is to map the state-of-practice in the design phase for a glulam building system from a platform theory perspective and outline a path forward for applying a sustainable platform development in companies where a component-based product platform does not suffice. Empirical data were gathered from an on-going product platform development including interviews and document analysis. The results show the lack of definition in platform-based product development from a theoretical perspective and need for development of support methods for design that align with different production strategies.
\end{abstract}

\section{KEYWORDS}

Product Platform, Industrialised house-building, Engineer-to-order, Glulam.

\section{INTRODUCTION}

The industrialized house building sector strives towards standardized and controlled processes in the design phase (Viklund, 2017). The demand for industrialized timber house buildings is getting increased attention (Jansson, 2013), where the glulam-based post and beam building system has been acknowledged as a feasible option for multi-

1 Ph.D. Student in Prowood Graduate Program. Product development department., School of Engineering, Jönköping, Sweden, +46702800583, shamnath.thajudeen@ju.se

2 Assistant Professor, Department of building engineering and lighting science, School of Engineering, Jönköping, Sweden, +4636101631, martin.lennartsson@ ju.se

3 Professor, Product development department., School of Engineering, Jönköping, Sweden, +46706401672, fredrik.elgh@ju.se 
storey buildings with timber (Tlustochowicz et al., 2010). Glulam is a structural timber member composed by at least two parallel laminations which may include one or two boards side by side having thicknesses from $6 \mathrm{~mm}$ up to $45 \mathrm{~mm}$ (BS EN 14080:2013). The building system composes of modular structures of main load-carrying members such as prefabricated beams and posts made of glulam with floor panels, wall and roof elements. The glulam system offers many advantages over other building systems such as element and volume types as well as being an attractive and versatile system for market demands (ibid). The changes towards industrialised house-building will have an influence on design, production and onsite work as a result of an increased use of prefabricated structural elements (Roy et al., 2003). The customization possibilities are highest in Engineer-to-order (ETO) based companies since customer involvement is allowed early in the engineering phase of the specification process (Hicks et al., 2000). The design phase of construction, in general, suffers from inefficiency in deliveries where time, cost and quality are not consistent with contracts (Tilley, 2005).

A platform, as a method of sharing components and processes allows the companies to develop differentiated products efficiently through a flexible and responsive processes (Robertson \& Ulrich, 1998; Meyer, 1997). For companies applying a product platform concept, prefabricated solutions could be a path forward to efficiently comply with customer demands. The automotive industry, e.g. Scania trucks, has introduced platform approach as a successful strategy for cross-product and process reuse (Robertson \& Ulrich, 1998). The practice of a platform-based product development approach could be a path forward, concerned with the design and also support customers, purchasing, inhouse production and site assembly that is capable of meeting the demand and exhibits less lead time in whole construction processes (Jansson, 2013). One of the main reasons for less development in the house building industry is the high amount of customization requirements from the customer (ibid). Several research studies have pointed out the benefits of adopting prefabrication (Höök, 2008), modularization (Jensen, 2010) and standardisation (Roy et al., 2005) in the house building sector, but applying a product platforms approach linked to the design phase is not well-developed.

However, a platform-based product development and implementation of a methods that supports a platform concept creates a research gap in the field of glulam based multistory timber house building sector where demands from clients must be fulfilled within a narrow timeframe. The aim of this work is to map the state-of-practice in the design phase for a glulam building system from a platform theory perspective and outline a path forward for applying a sustainable platform development in companies where a component-based product platform does not suffice. The impact on the current practice and future state of the design phase has been analysed and discussed. The scope is delimited to the design phase where a single case study has been carried out.

\section{RESEARCH METHODOLOGY}

The Design Research Methodology (DRM) was adopted for this study (Blessing \& Chakrabarti, 2009). DRM is a four-stage iterative process used for conducting research in the engineering design field to develop innovative solutions that solve practical problems and allows a theoretical contribution. Research clarification is the initial stage where the 
researcher tries to find support or evidence to formulate the goal. In the Descriptive Study phase, the researcher has a clear goal and the empirical data collection and analysis can be done to gain deeper knowledge by accessing the current state. The prescriptive study is the third stage where the researcher starts the systematic development of new support for the improvement of an existing problem. The researcher then proceeds to the final stage which is the Descriptive Study II (DS-II) stage to investigate the impact of the support method and its ability to realize the desired situation.

DRM is used as a framework for the whole research project and this paper covers the two initial phases where a literature review was done in the research clarification phase followed by the collection and analysis of empirical data from the case company as part of the first descriptive study phase. The research approach was qualitative in nature with literature studies combined with a case study strategy. Multiple sources of evidence were scrutinized with semi-structured interviews and document analyses. The interviews were carried out with five respondents, Managing Director, Design Manager, Structural Engineer, Design Engineer and Project manager with open-ended questionnaires. Besides, the documents analysed included the structural calculations, 2D drawings, 3D models of buildings, excel spread sheets and activity plans for different projects etc.

\section{LITERATURE REVIEW}

There are four types of product specification processes according to Hansen (2003) for meeting the client needs which depend on the four production strategies engineer-to-order (ETO), modify-to-order (MTO), configure-to-order (CTO) and select variant (SV) as shown in Fig. 1. ETO companies offers highly customized products where the product specification process starts based only on norms and standards, e.g. Construction industry. The MTO companies produce customized product based on technical platforms (Jensen, 2010), e.g. Manufacturing industry and according to Hvam et al. (2008), the MTO or ETO processes are appropriate when the product is complex or more creativity in design is required. CTO products are produced based on modules and the standard parts are evaluated according to a set of predefined rules, e.g. Software industry. The last one, select variant, is a process in which a standard product fulfill the customer's needs e.g. Automotive industry. To achieve the benefits from the use of platforms, the company has to postpone the customer order decoupling point (CODP), the point where customer meets suppliers, to a later stage of the value chain (Bonev et al., 2015). 


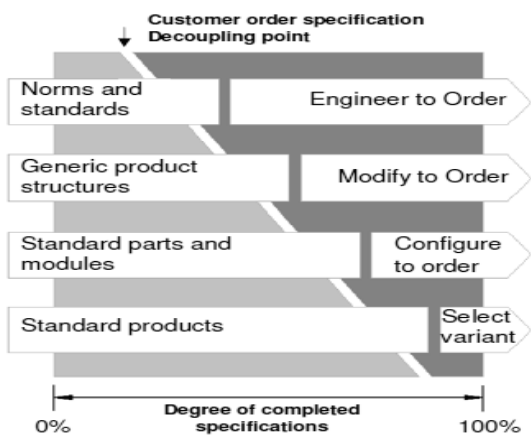

Figure 1: - Product specification process (Hansen, 2003)

The use of product platforms has been acknowledged as an enabler to manage external (customer) and internal (production) efficiency. Robertson \& Ulrich (1998) define the fundamentals of platform which consists of four parts - components, processes, knowledge and relationships. Components are the building blocks used when designing a product and designing component-specific tools for manufacturing. The processes include the tasks involved in the different phases such as design, production process and assembly. Knowledge is described by the technical and design knowledge, knowledge transfer between projects, production and assembly knowledge including testing. Relationships concern interactions internally between team members, and externally with organisations, networks with suppliers and the broader supply chain. These assets are critical in the development of platform strategy for any business settings. A platform contains a core of technology and is defined as "A set of common components, modules or parts that form a common structure from which a stream of derivative products can be efficiently developed and produced" (Meyer, 1997). A platform approach can be of two kinds, where the first one is module- based (discrete) and characterized by sets of components being clustered into interchangeable modules that together form the product (Elgh et al., 2016). The second one is scalable platform supporting adaptation by stretching or shrinking the product instances following variations in design variables. Both approaches, support the generation of product families, which is a group of different products generated from a common set of components (modules) and have a number of common characteristics (Hvam et al, 2008). The product development and production strategy based on platforms have been successfully implemented in industries such as automotive, electronics and software etc., but not well developed in house industry.

Customer involvement in the product development of house building and the ETO production strategy hinders the implementation of a fully parameterized platform (Jansson et al., 2014). The introduction of platforms within house-building causes contractors to move from ETO towards MTO oriented production, which Winch (2003) describes as a transition towards mass customization. The implementation of product platforms by standardisation of the products and process has been considered as a challenge in the construction sector (Jansson, 2013).

The practice of reusing processes and technical solutions leads to the design of product platforms for house building (Jansson et al., 2014). The design process is challenging and has multi-disciplinary tasks in all the product development projects. 
Normally, the design process starts with conceptual design by the architectures and continues through design development which including systems design, and detailed design (Jansson, 2013). Viklund (2017) studied the advantage of integrating the platform in the design phase of industrialized house building. By predefining building systems and technical solutions in product platforms, parts of the design process can be integrated and used for platform development (Jansson et al., 2014). Standardised processes for repetitive work to better utilise resources as well as ensuring that knowledge of the product and the building system is captured within the system itself, not only by persons working in it (Jansson et al., 2008). By controlling the design process in house-building and making that process more efficient, a higher quality of product development is achieved which supports to avoid the re-planning of design work (Jansson et al., 2013). The repetitive processes in design offer a foundation for treating those processes as commonalities in the process platform asset (ibid). The literature review indicates that a strict platform theory does not fit in this context and is difficult to adopt for companies working with a combination of production strategies.

\section{SINGLE CASE STUDY - STATE OF PRACTICE}

The case company is a glulam producer with the world's oldest glue-wood factory and is one of the leading glued-wood manufacturers in Europe. The factory was founded in 1919 and employs 137 peoples. The total production capacity is 55,000 $\mathrm{m}^{3}$ annually with a turnover of 28 million EURO. The company is part of a Scandinavian industrial group that manufactures building products and systems to the construction sector. The group has production facilities in 50 locations and employs approximately 3,400 peoples.

\section{THE BUILDING SYSTEM}

The building system was launched in 2007, which was one of the major innovations in post and beam building system. It is ideal for a hybrid building system where materials such as concrete, steel components are also used with timber during the construction to create a strong building base. The building system allows an 8-meter span, that enables space for architects. To have the proper stabilization of the buildings, the stair-wells and elevator shafts are constructed of concrete and all the connections between posts and beams made by steel components. The offer includes an engineered structure, designed from static considerations, for the multi-storey building including support frames with posts and beams, connectors for post and beams, intermediate floor element insulated with mineral wool and roof elements. The assembly and erection of elements have been carried out by either customers or with the support from a partner contractor.

The process mapping and flow of information during the structural and design phase are shown in fig. 2. The main tools used are software such as Stat-Con, Truss-Con, Mathcad for structural calculations, Finite Element Method (FEM) programs such as RSTAB, RFEM and excel sheets for summarizing the loads by structural engineers. Tekla structure and AutoCAD are used for drawing and modelling 2D and 3D design by design engineers. Parametric CAD models in Tekla structures are also used for a few projects to expedite the modelling. The structural calculations start with the help of 
documents and standard references such as drawings from customers, standard reference by law and permanent loads according to the scope of the project. The total loads acting on the foundation must be calculated and transferred to subcontractors who deal with the concrete foundation works. Then, the calculations for posts are done initially, then the beams and then the trusses by considering the permanent loads of posts, beams, trusses etc. The next step is to calculate the total load on the concrete structure (elevators and staircases). A predefined spread-sheet is used to put in the standard loads for wind, snow, permanent etc. which automatically generates the output of required loads that need to be designed. Stat-con structure is used to calculate the dimensions of posts and beams. Mathcad is used for the calculations of floor elements and detailing of all the steel brackets and connectors. Once the dimensions are extracted for posts and beams, the structural engineer starts with the calculations of floor elements and other components. An AutoCAD drawing is generated with all the values of loads and parameters that should be references for the design engineer to model the entire building in Tekla structure. As shown in figure 2, the finished drawings from Tekla structure will be forwarded to the different stakeholders in the project such as suppliers, customers, production and on-site assembly operations.

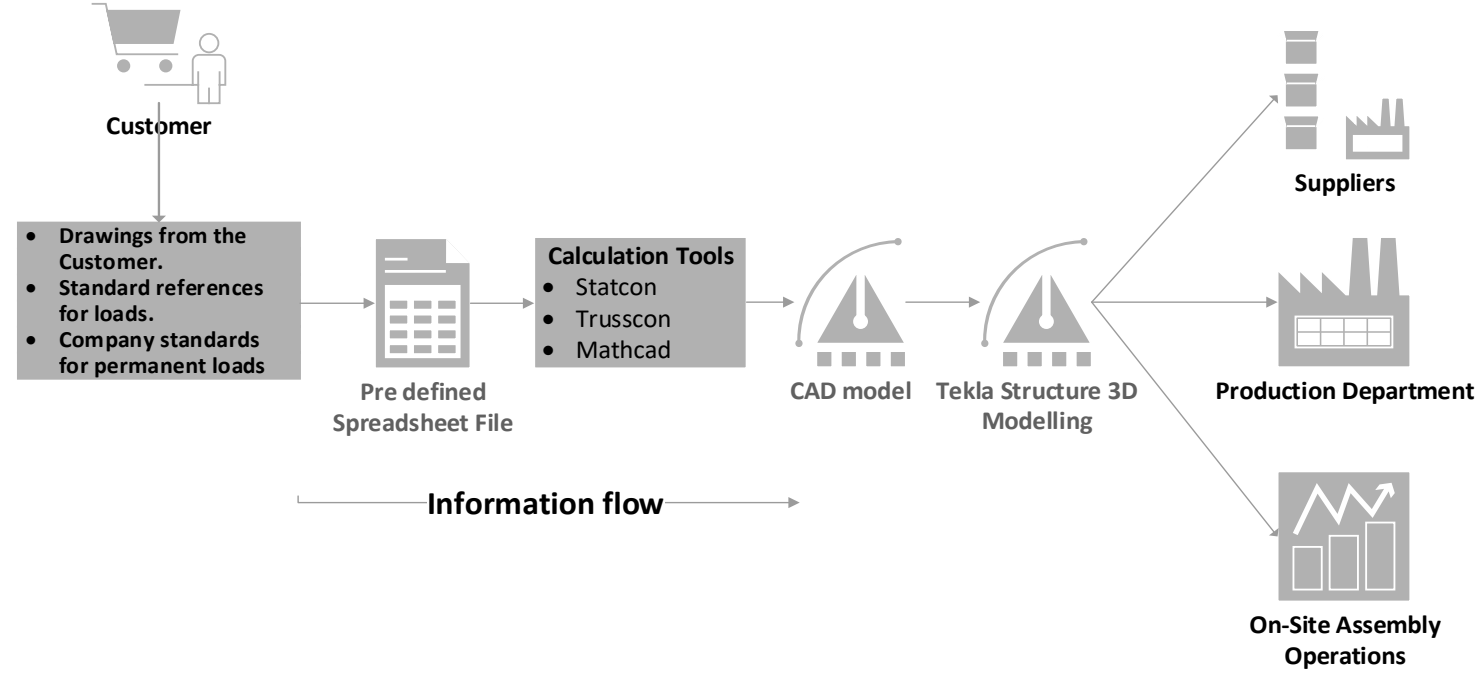

Figure 2: The Design process at case company

\section{CASE ANALYSIS AND DISCUSSION}

The company is working both with the ETO and MTO where customised buildings are developed upon customer requests based on norms and standards linked to the building system. The products offered by the company based on the building system are customer specific and have been executed accordingly to the demands from the customer. Robertson \& Ulrich (1998), define components, processes, knowledge and relationships as the collection of assets for house-building platforms that combine to form the product.

For the components, the company has partly defined the components that can be derived from the building system. No product family has been developed from the building system and it includes some standardized components such as steel connections, 
joints, foot of columns connector and standard fittings for connection between column and beams.

The processes in the design phase has not been standardized and the sequence of work is not clearly defined which makes it difficult to manage many projects at same time. The traditional way of executing the projects has been identified at the company and processes are not well-developed either in technology nor product development. The people working within the structural and design phase develops their own methods individually to simplify their works, by finding the similar tasks or repetitive tasks, e.g. custom components by a design engineer, excel platform by a structural engineer.

For the knowledge asset, the individual learning is happening between the projects, for example, the design engineer working with the projects is learning from previous projects and manage to develop better solutions for future projects. The company has developed a parametric CAD model to a certain level that can be used for a different project to some extent, but they are not developed completely to have access for all designers. The designers are using a components library customised for projects where they execute the design process of many components used in the projects and reuse the components as much as possible to reduce the lead time. The current library is not fully defined, developed and organized as it has some brackets, column footings only. The design engineer has been following an approach and make some assessments individually during the design of building components which support the production and assembly team to make sure that the components can be easily produced and assembled at the site during erection e.g. sequence marking on floor elements and connectors. However, it has not been well-documented or supported with guidelines and without means to share.

For the final asset, the relationships internally and externally, they are not wellaligned and no protocol to follow currently. The main external support is from sister companies with the guidance, recommendations from partner company for acoustics expertise and sub-contracting company who provides dynamic calculations for different project that need special skills. The company does not have a formal system to collect and analyse customer feedback. Most solutions are developed within the projects. However, according to Lessing (2006), It is important to separate the development of a product platform from individual projects. The platform assets have been related and analysed to identify the issues and understand the current state of platform definition at the case company. The current platform is not structured enough to follow for stakeholders and defined boundaries and components are missing which mismatch with theory. The view and understanding of platform-based product development among the respondents appear far from the theory as they were not familiar with the term and concept of platform.

\section{APPLYING PRODUCT PLATFORM APPROACH}

To meet the increasing demands of building system from the market, the company could develop a platform approach that supports both external stakeholders such as customer, suppliers and internally in design, production and site assembly operations in an efficient way. The gap between the theoretical review and practice was in terms of design support 
methods of platform development. As an act to improve, the support methods such as design planning, collaborative design, design optimization and requirement iterations should be developed. As Jansson et al., (2014) argue, the design support methods for daily engineering works are required to link the gap between the standardized platform and the project specific parameters and applying the methods can highlight different assets in the platform. It is significant to develop support guidelines in the design phase that helps to evaluate and guide the solutions that developed can also be efficiently manufacture and assembly concern to design for manufacturing (DFM) and design for assembly (DFA). The effective planning and efficient management of the design phase is important to consider by investigating all the included tasks and deliverables.

A platform perspective facilitates value focus for both the customer and the producer, i.e. adding support for the stakeholders to decide what to standardise to create value for customers and move further from the traditional construction to lean construction (Maxwell \& Aitchison, 2017). Currently for the case company, both the knowledge and the relationship assets are not emphasizing this issue, adding a risk when applying a platform approach. For example, this could help the company to reduce non-value adding works, variability, less lead time and unnecessary wastes which basically is, the lean way of design and manufacturing (Jansson et al., 2008). This could also benefit to differentiate the repetitive activities and unique activities within the design to develop the requirement iterations in a smart way. The design collaboration could be achieved through regular daily meetings within the design and other departments and acts according to the plan. Also, the design optimization by implementing a feedback management system should be developed for the continuous improvement from both internal and external sources which is highly critical for the company (Jansson, 2013). The feedback reports from the client should be analysed and modifications implemented to the engineering work process. The development of a well-defined platform will offer the customers to choose their products which are defined within the platform boundaries that outline the product family. Fig. 3 shows the representation of a desired product platform support essential for the company. 


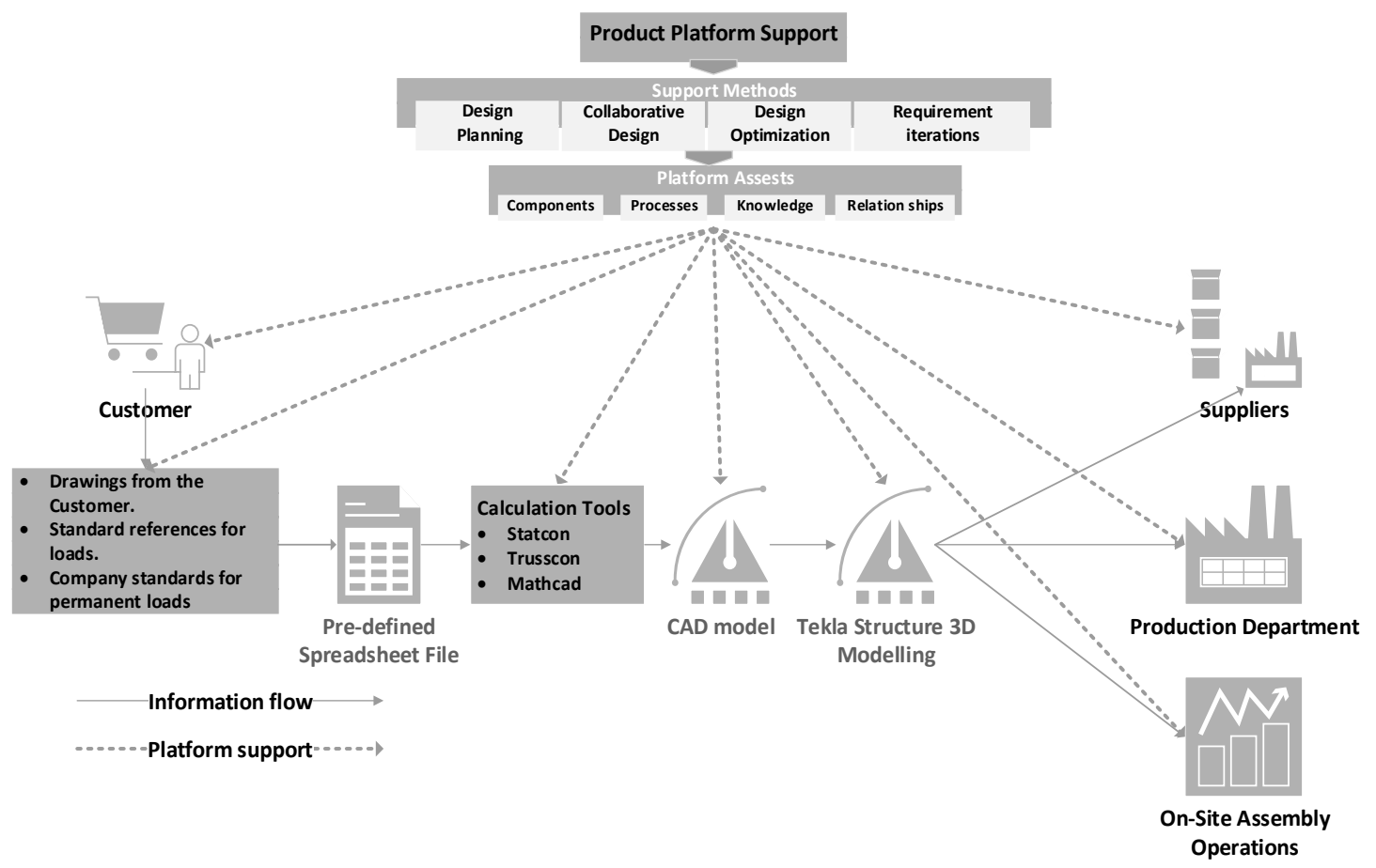

Figure 3: Platform support in detailed design phase

The definition of support methods will help to align the platform assets which makes a high impact on the design phase, which was the objective of this study. It is recommended to adopt a strategy where step by step development of the process in some parts of the system, evaluate, improve them slowly could result in an incremental development of the product platform. The development of well-defined product platform approach could support the case company to identify the product structure, distinguish the components into different process flow to avoid interactions within the design phase, support those with different methods and tools and finally improve and optimize the individual flow.

\section{RESEARCH OUTLINE AND CONCULSIONS}

This study indicates a lack of theoretical knowledge in the area, how the combination of different production strategies could work well and align with the companies operating in same sector as case company. It is significant for the case company to develop their business model based on the principles of product specification process illustrated by Hansen (2003). From the product concept described, it is evident that the company cannot stay completely in a specific production strategy as some components of building system can be standardized and have a modular approach, some parts comes in configured approach and some parts are yet to be in engineer-to-order that should be altered and customize according to customer needs. Some standard components and modules can be derived to a certain extent with the help of the platform support methods to generate solutions, evaluate and ensure that they are fulfilling the requirements from client and can be easily be produced in production and assembly at site. It shows that the theory is not 
well-defined and completely applicable on the case company, implies a mismatch and outline the research gap on this field. From the analysis of state of practice at case company, it is clear that they cannot develop a fully predefined and fixed platform system for all the products as the projects are customer-driven. The combination of manufacturing strategies suits better for these types of companies in the construction sector where some subcomponents from the building system suits for configure-to-order, few parts fits in modify-to-order process and rest to fulfil the unique needs of customers. The future research shows the path forward to develop the knowledge in theoretical field that defines the methods and criteria's to be considered when transforming companies into a product platform strategy that also contributes the scientific knowledge in the field.

The case company has the potential to achieve high levels of product variety, reduced time to market, better operational efficiency and responsiveness to the market needs with the support of product platforms. The impacts on the design phase when applying the product platform in the glulam-based building system have been analysed based on the platform knowledge perspective, which are the main platform assets defined by Robertson \& Ulrich (1998) and support methods described by Jansson et al. (2014) together constitutes a path forward for sustainable platform development for the case company. The objective of this paper was to investigate the state-of-practice in the design phase from platform theory perspective. The mapping of processes revealed the lack of definition in platform-based product development from theoretical point of view. It seems to be challenging to strictly apply the definition of platform approach in these kinds of companies working with a combination of production strategies. The results point out the need of knowledge development including methods and tools, supports the design phase and to ensure that solutions offering to customer are within the boundaries of the platform.

\section{ACKNOWLEDGMENT}

We would like to thank the case company and all participating respondents, Prowood and the knowledge foundation for the financial support of this research.

\section{REFERENCES}

Blessing, L. \& Chakrabarti, A. (2009). DRM: A Design Research Methodology: Springer, London.

Bonev, M., Wörösch, M., \& Hvam, L. (2015). Utilizing platforms in industrialized construction: A case study of a precast manufacturer. Const. Innovat., 15(1), 84-106

Elgh, F., André, S., Johansson, J., \& Stolt, R. (2016). Design Platform: Setting the Scope and Introducing the Concept. presented at DESIGN 2016, 14th Int. Design Conf.

Hansen, B. L. (2003). Development of industrial variant specification systems. Doc diss, IKON Tekst \& Tryk A/S.

Hicks, C., McGovern, T., \& Earl, C. F. (2000). Supply chain management: A strategic issue in engineer to order manufacturing. Intl. J. of Prod. Eco., 65(2), 179-190.

Hvam, L., Mortensen, N. \& Riis, J. (2008). Product customization. Springer Sci \& Bus.

Höök, M. (2008). Lean culture in industrialized housing: a study of timber volume element prefabrication, Doctoral dissertation, Luleå, Sweden 
Jansson, G. (2013). Platforms in industrialised house-building. Luleå tekniska universitet. Jansson, G., Johnsson, H., \& Engström, D. (2014). Platform use in systems building. Construction Management and Economics, 32(1-2), 70-82.

Jansson, G., Johnsson, H., \& Jensen, P. (2013). Modularization in a housing platform for mass customization, In Annual ARCOM Conference: 02/09/2013-04/09/2013

Jansson, G., Söderholm, E., \& Johnsson, H. (2008). Design process organisation at industrial house builders: a case study of two timber housing companies in Sweden. Paper presented at the Annual ARCOM Conference: 01/09/2008-03/09/2008.

Jensen, P. (2010). Configuration of modularised building systems, Doc diss, Luleå, Sweden

Lessing, J. (2006). Industrialised house-building. Concept and Processes.

Maxwell, D. W., \& Aitchison, M. (2017). Design-value in the platform approach. Paper presented at the IGLC 2017 - Proceedings of the 25th Annual Conf of the IGLC.

Meyer, M. H. (1997). The power of product platforms: building value and cost leadership. New York: New York: Free Press.

Robertson, D., \& Ulrich, K. (1998). Planning for product platforms. Sloan mgmt rev, 39(4), 19-31.

Roy, R., Brown, J., \& Gaze, C. (2003). Re-engineering the construction process in the speculative house-building sector. Constr. Manage. and Economics, 21(2), 137-146.

Roy, R., Low, M., \& Waller, J. (2005). Documentation, standardization and improvement of the construction process in house building. Const. Mana. and Econ., 23(1), 57-67.

Tilley, P. A. (2005). Lean design management: a new paradigm for managing the design and documentation process to improve quality? IGLC-13, Sydney Australia

Tlustochowicz, G., Kermani, A., \& Johnsson, H. (2010). Beam and post system for nonresidential multi-storey timber buildings: conceptual framework and key issues. In World Conference on Timber Engineering: 20/06/2010-24/06/2010

Viklund, E. (2017). Design approaches in industrialized house building: A creativity perspective: Ett kreativitetsperspektiv, Doc. diss Luleå, Sweden

Winch, G. (2003). Models of manufacturing and the construction process: the genesis of re-engineering construction. Building Research \&amp; Information, 31(2), 107-118. 